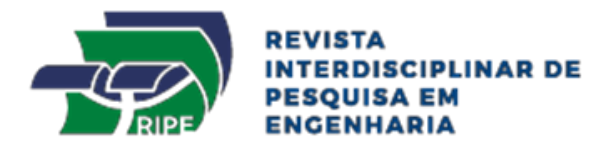

\title{
BIOÉTICA NA PESQUISA ENGENHARIA BIOMÉDICA: DIMINUIÇÃO DO USO DE ANIMAIS EM EXPERIMENTOS CIENTÍFICOS
}

\author{
Marcos A. M. Fonseca ${ }^{1,2}$, Glécia V. S. Luz ${ }^{1,2}$, Paulo R. Santos ${ }^{2,3}$, Cássia C. M. Viveiros ${ }^{2,4}$, Suélia R. F. \\ Rosa $^{1,2}$ \\ ${ }^{1}$ Programa de Pós-Graduação em Engenharia Biomédica-PPGEB, Faculdade do Gama- FGA, \\ ${ }^{2}$ Universidade de Brasília-UNB - St. Leste Projeção A - Gama Leste, Brasília - DF, 72444-240, Brazil, \\ ${ }^{3}$ Programa de Pós-Graduação em Sistemas Mecatrônicos-PPMEC, UNB, \\ ${ }^{4}$ Programa de Pós-Graduação em Nanociência e Nanobiotecnologia-PPGNANO, UNB,
}

e-mail: marcos.fonseca2@gmail.com

Resumo: Atividades de pesquisa utilizando animais são realizadas desde a antiguidade, o bemestar do animal não era prioridade. Com a evolução da pesquisa, houve, também, a crescente preocupação com a ética e métodos que poderiam substituir o uso de cobaias animais nos experimentos científicos. Tal conscientização manifestou-se já no início do século XIX, na Inglaterra, com o surgimento de movimentos que se dedicavam a mudar as atitudes do homem em relação aos animais. Desde então, ativistas argumentam que métodos alternativos são capazes de substituir a utilização de animais em pesquisa, e que, por isso, a utilização de seres vivos é considerada como obsoleta. Por outro lado, alguns cientistas argumentam que a experimentação é o que traz frutos das pesquisas. $O$ presente trabalho apresenta um levantamento de dissertações e teses defendidas no Instituto de Biologia da Universidade de Brasília no ano de 2017 que realizaram testes in vitro e in vivo além de trazer uma reflexão sobre o assunto e visa ressaltar as vantagens do uso de métodos alternativos. Para este estudo, foram utilizados artigos e dissertações das bases de dados CAPES e PubMed, bem como outras referências presentes neles. Concluiu-se que, embora não haja tecnologia suficiente para erradicar o uso de animais em experimentos, existem diversos métodos alternativos que não comprometem o estudo realizado.

Palavras-chaves: Experimentação animal, bioética, bem-estar animal, ética em pesquisa, engenharia biomédica

\begin{abstract}
Research activities using animals have been carried out since antiquity, animal welfare was not a priority. With the evolution of research, there was also a growing concern about ethics and methods that could replace the use of animal guinea pigs in scientific experiments. Such awareness began to manifest itself in the early nineteenth century in England with the emergence of movements that were dedicated to changing man's attitudes towards animals. Since then, activists have argued that alternative methods are capable of replacing the use of animals in research, and, therefore, the use of living beings
\end{abstract}




\section{Revista Interdisciplinar de Pesquisa em Engenharia}

is considered obsolete. On the other hand, some scientists argue that experimentation is the fruit of research. The present work presents a survey of dissertations and theses defended at the Institute of Biology of the University of Brasília in the year 2017 that carried out in vitro and in vivo tests, besides bringing a reflection on the subject and aims to highlight the advantages of the use of alternative methods. For this study, articles and dissertations of the CAPES and PubMed databases were used, as well as other references present in them. It was concluded that, although there is not enough technology to eradicate the use of animals in experiments, there are several alternative methods that do not compromise the study.

Keywords: Animal experimentation, bioethics, animal welfare, research ethics, Biomedical engineering

Resumen: Las actividades de investigación utilizando animales se realizan desde la antigüedad, el bienestar del animal no era prioridad. Con la evolución de la investigación, también hubo una creciente preocupación sobre la ética y los métodos que podrían reemplazar el uso de conejillos de indias en experimentos científicos. Tal conciencia comenzó a manifestarse a principios del siglo XIX en Inglaterra con el surgimiento de movimientos que se dedicaron a cambiar las actitudes del hombre hacia los animales. Desde entonces, los activistas han argumentado que los métodos alternativos son capaces de reemplazar el uso de animales en la investigación y, por lo tanto, el uso de seres vivos se considera obsoleto. Por otro lado, algunos científicos sostienen que la experimentación es el fruto de la investigación. El presente trabajo presenta una encuesta de disertaciones y tesis defendidas en el Instituto de Biología de la Universidad de Brasilia en el año 2017 que llevó a cabo pruebas in vitro e in vivo, además de traer una reflexión sobre el tema y tiene como objetivo resaltar las ventajas de la uso de métodos alternativos. Para este estudio, se utilizaron artículos y disertaciones de las bases de datos CAPES y PubMed, así como otras referencias presentes en ellos. Se concluyó que, aunque no hay suficiente tecnología para erradicar el uso de animales en experimentos, existen varios métodos alternativos que no comprometen el estudio.

Palabras clave: Experimentación animal, bioética, bienestar animal, ética en investigación, Ingeniería Biomédica

\section{INTRODUÇÃO}

Experimentação animal constitui-se em procedimentos laboratoriais realizados em animais, que tem como objetivo descobrir princípio ou efeito desconhecido, pesquisar uma hipótese ou ilustrar um princípio ou fato conhecido (PAIXÃO; SCHRAMM, 2001). Segundo os autores, o termo "experimentação animal" pode se referir a dois tipos de pesquisa, a saber: a um estudo que visa conhecer melhor o próprio animal; ou a um estudo que pretende descobrir possíveis aplicações na saúde e bem-estar deles. Ademais, frequentemente, esses seres são usados como modelos em outras pesquisas que visam o bem-estar dos seres humanos, pesquisas estas que são alvo de constantes críticas. 


\section{Revista Interdisciplinar de Pesquisa em Engenharia}

Distingue-se a ética na Engenharia Biomédica ao se comparar com outros ramos da engenharia, pois ela está diretamente ligada aos serviços de saúde, sejam preventivos ou de tratamento. A ética desempenha um papel relevante dentro da Engenharia Biomédica, particularmente em pesquisas, nas quais constam atividades que vão desde experiências em bancadas até experimentos com animais. Cursos de ética na engenharia biomédica fornecem a base para o reconhecimento de questões éticas, pois conscientizam estudantes a respeito da importância de se ter uma conduta ética (CHAN et al., 2013).

É importante que engenheiros biomédicos entendam o impacto de não cumprir normas éticas. Existem regulamentações, como diretrizes internacionais e leis, com as quais as empresas desejam se alinhar para protegerem seus acionistas. Estas normas são elaboradas pelo Conselho Nacional de Saúde, competindo, por outro lado, aos Comitê de Ética em Pesquisa (CEP), Comissão Nacional de Ética em Pesquisa (CONEP) e Comissão de Ética no Uso de Animais (CEUA) a homologação projetos de pesquisa. Assim, a ética necessita ser vista como uma parte integral do trabalho de um engenheiro biomédico. A dependência e o impacto da tecnologia na Saúde aumentam continuamente. Deste modo, engenheiros biomédicos são, cada vez mais, vistos como parte integral do serviço de saúde e, portanto, possuem grande responsabilidade.

As diferentes formas de utilização de animais que se enquadram no campo da “experimentação animal”, atualmente são divididas em sete categorias principais (PAIXÃO, 2001):

$\checkmark$ Pesquisa básica - biológica, comportamental e psicológica. Refere-se à formulação e testes de hipóteses sobre questões teóricas fundamentais, tais como, a natureza da duplicação do DNA, a atividade mitocondrial, as funções cerebrais, o mecanismo de aprendizagem, enfim, com pouca relevância para o efeito prático dessa pesquisa;

$\checkmark$ Pesquisa aplicada - biomédica e psicológica. Formulações e testes de hipóteses sobre doenças, disfunções, defeitos genéticos, etc., as quais não há necessariamente consequências. Incluem-se nesta categoria os testes de novas terapias: cirúrgicas, terapia gênica, tratamento a base de radiação, tratamento de queimaduras, etc;

$\checkmark$ O desenvolvimento de substâncias químicas e drogas terapêuticas. A diferença entre essa categoria e as anteriores é que aqui se refere ao objetivo de encontrar uma substância específica para um determinado propósito, mais do que o conhecimento por si próprio; 


\section{Revista Interdisciplinar de Pesquisa em Engenharia}

$\checkmark$ Pesquisas voltadas para um aumento da produtividade e eficiência dos animais na prática agropecuária;

$\checkmark$ Testes de várias substâncias quanto à sua segurança, potencial de irritação e grau de toxicidade, tais como cosméticos, aditivos alimentares, herbicidas, pesticidas, químicos, industriais e drogas;

$\checkmark$ Uso em instituições educacionais para demonstrações, vivisseções, treinamento cirúrgico, indução de distúrbios com finalidades demonstrativas e projetos científicos.

$\checkmark$ Uso para extração de drogas e produtos biológicos, tais como vacinas, sangue, soro, anticorpos monoclonais, proteínas de animais geneticamente modificados para produzilas, dentre outros.

Além destes, existe o campo de estudos com animais silvestres e/ou selvagens, cuja parte significativa da pesquisa envolve um trabalho de campo, no qual os animais permanecem em seu habitat (DONELLY \& NOLAN, 1990 apud PAIXÃO; SCHRAMM, 2001).

Um outro tipo de experimentação que envolve animais é a chamada "pesquisa militar", que inclui o desenvolvimento de armas e seus testes. Os animais são submetidos a armas químicas, radiações ionizantes, laser, microondas à alta potência e armas biológicas (BUDKIE, 2001 apud PAIXÃO; SCHRAMM, 2001). Este artigo tem por objetivo de quantificar as dissertações e teses defendidas no Instituto de Biologia da Universidade de Brasília no ano de 2017 que realizaram testes in vitro e in vivo, apontar alternativas ao uso de animais em experimentos científicos existentes atualmente no mercado mundial, além de incitar a uma reflexão a respeito do tratamento dado aos animais, de maneira a conscientizar todos os envolvidos sobre a necessidade de realizar pesquisas e atividades didáticas de forma adequada, com respeito às normas estabelecidas por comitês de ética de pesquisa e aos animais utilizados para tal fim.

\section{METODOLOGIA}

Para este estudo utilizou-se a base de dados PubMed para localizar os artigos usados na presente pesquisa. Para tanto, empregaram-se as palavras-chave "animal experimentation alternatives" (do inglês, alternativas a experimentação animal) e bioethics (do inglês, bioética). Os critérios de inclusão para a seleção dos artigos foram:

$\checkmark$ Ter sido escrito nas línguas Portuguesa ou Inglesa;

$\checkmark$ Ter menos de dez anos da data de publicação; 


\section{Revista Interdisciplinar de Pesquisa em Engenharia}

$\checkmark$ Possuir uma avaliação ética do uso de animais em experimentos;

Foram inclusos, ainda, livros, dissertações e teses disponibilizadas na biblioteca digital da UNB.

\section{HISTÓRICO DO USO DE ANIMAIS EM PESQUISA}

O uso de animais pelo Homem é uma prática antiga. Desde a época em que os homens viviam em cavernas e encontravam na caça um meio de sobreviver. Assim, os animais foram utilizados ao longo da História como fonte de alimento, meio de transporte, no lazer, em esportes, na religião dentre outras atividades, sempre objetivando o conforto do Homem, sem que houvesse preocupação do bem-estar animal (FRANCO et al., 2014).

Aristóteles (384-322 A.C.) declara uma estrutura hierárquica do mundo e a existência de diferenças essenciais entre seres humanos e animais. Diferenças estas que tornam o Homem superior aos animas não humanos, tendo como consequência a sobreposição do superior (o Homem) sobre o inferior (o animal). A partir desse conceito de superioridade, diversas atividades didáticas e científicas utilizaram-se de animais, com o objetivo de aprofundar o conhecimento a respeito de determinado assunto. Todavia, não havia a exigência da aplicação de um método sistematizado de investigação.(ZWOLIŃSKA, 2013)

Este raciocínio também é partilhado por René Descartes (1596-1650), que considera que os processos de pensamento e sensibilidade correspondem à alma e, segundo as tradições Judaico-cristãs e Islãs, a alma é inerente ao ser humano, mas não aos animais. Portanto, por serem desprovidos de uma alma, não haveria possibilidade de os animais sentirem dor. Consequentemente, neste período, as investigações científicas passaram a ser menos observacionais e descritivas, assumindo um caráter mais invasivo e experimental (ZWOLIŃSKA, 2013) .

Por séculos, a atitude humana perante os animais foi predominantemente de domínio e a partir dos anos 1800, o uso de animais em pesquisa e ensino ascendeu-se, mesma época em que começaram a surgir as primeiras sociedades protetoras dos animais. Neste contexto, em 1822, foi promulgada uma das primeiras leis a proteger animais, a British Anticruelty Act (do inglês, Lei Inglesa Anti-crueldade), também conhecida por Martin Act, em memória de seu assíduo defensor, Richard Martin (1754-1834). Ressalta-se, porém, que esta norma protegia apenas animais domésticos de grande porte (RICOU; MESTRADO, 2010). 


\section{Revista Interdisciplinar de Pesquisa em Engenharia}

Somente em 1876, com o British Cruelty to Animals Act (do inglês, Lei de Crueldade com Animais), houve uma busca para regulamentar a pesquisa em animais. Contudo, a proposta não foi bem recebida pela comunidade científica da época (FRANCO et al., 2014). A partir de então, várias outras instituições protecionistas foram criadas, várias legislações surgiram em outros países, dessa maneira, o debate a respeito do uso dos animais progrediu tanto no âmbito científico, como no filosófico.

Como reflexo desse debate sobre a questão do sofrimento animal, que se desenvolveu simultaneamente à prática da experimentação animal, ocorreu o surgimento daquilo que pode ser considerado como uma referência para a ciência contemporânea que utiliza animais de laboratório: o conceito dos "3Rs" - replacement, reduction e refinement (do inglês, substituição, redução e refinamento). Essa definição foi estabelecida em 1959 pelo zoologista William M.S. Russell e o microbiologista Rex L. Burch no livro The Principles of Humane Experimental Techniques, e declara que os danos causados a animais em estudos podem ser minimizados, ou até mesmo prevenidos, sem comprometer a qualidade da pesquisa científica (LANDI; SHRIVER; MUELLER, 2015). Conforme a definição dos “3Rs”, os animais podem ser preservados de possíveis riscos físicos através das técnicas estabelecidas:

$\checkmark$ Replacement - indica que, em uma pesquisa com potencial risco, deve-se substituir um organismo consciente por material não consciente, tais como plantas, microorganismos etc (CHELUVAPPA; SCOWEN; ERI, 2017);

$\checkmark$ Reduction - preconiza que o estudo seja planejado cuidadosamente, com o objetivo de minimizar os grupos de estudo (CHELUVAPPA; SCOWEN; ERI, 2017);

$\checkmark$ Refinement-sugere que sejam tomados os cuidados devidos para que seja reduzido o desconforto ou sofrimento animal.

Esta proposta representa o impulso inicial na comunidade científica do conceito de “alternativas". Ela não impede a utilização de modelos animais em experimentação, mas faz uma adequação no sentido de humanizá-la, podendo também ser aplicada às atividades didáticas.

Apesar desta abordagem ter proporcionado um significante progresso à saúde dos animais na pesquisa os 3Rs ocasionalmente são tratados como um obstáculo burocrático. A política dos “3Rs", por diversas vezes, é efetivada como apenas uma listagem de normas, ignorando discussões aprofundadas e análises completas do aprimoramento orientado pelo conhecimento de diversas opiniões éticas acerca dos animais. 


\section{Revista Interdisciplinar de Pesquisa em Engenharia}

\section{EXPERIMENTAÇÃO ANIMAL NO BRASIL}

No Brasil, não existe lei que regulamente a utilização de animais em pesquisa científica. Algumas instituições nacionais criaram algumas normas que dizem respeito a pesquisas animais, e têm como objetivo orientar pesquisadores a respeito do uso de animais em experimentos.

A Lei n. $6.638 / 79$ foi a primeira a estabelecer normas para a prática didático-científica em animais; entretanto, este preceito normativo não aborda o princípio dos “3R". Ademais, a Lei n. 6.638/79 possui caráter protetivo, tendo em vista que proíbe a realização da atividade sem emprego de anestesia ou sem supervisão de um técnico especializado. Apesar das críticas quanto a abordagem ética, esta norma não permite a realização da experimentação animal em estabelecimentos de ensino de primeiro e segundo graus, bem como em locais frequentados por menores (MEDEIROS; ALBUQUERQUE, 2015).

Após a Lei n. 6.638/79, foi promulgada a Lei n. 9.605, em 12 de fevereiro de 1998, que dispõe a respeito das sanções penais e administrativas que incidem sobre condutas e atividades lesivas ao meio ambiente. Outrossim, esta lei também regulamenta a fauna doméstica e de laboratório (MEDEIROS; ALBUQUERQUE, 2015).

Atualmente, a Lei n. 11.794/2008, conhecida como Lei Arouca, sancionada em 8 de outubro de 2008, normatiza as Comissões de Ética para o Uso de Animais (CEUAs), além do mais, essa mesma lei também criou o Conselho Nacional de Controle de Experimentação Animal (CONCEA). O CEUA é composto por cidadãos que examinam os protocolos, por isso, esta comissão é indispensável para o cadastramento das instituições. O CONCEA tem como objetivo a criação de normas que visam a garantia dos cuidados para com os animas, das instalações dos centros de criação, do uso humanitário dos animais. Por fim, este conselho também tem como finalidade a busca de técnicas alternativas para a substituição do uso de animais. O não cumprimento dessas normas implica em penalidades, que variam entre advertências, multas e interdições (PAIXÃO, 2013).

Os projetos de pesquisa que envolvem o uso de animais devem ser cuidadosamente planejados e realizados adequadamente em relação aos aspectos éticos e metodológicos. Os professores, ou pesquisadores, devem seguir certas diretrizes orientadoras para elaborar seus projetos experimentais. Como em todo o projeto de pesquisa, previamente a sua execução, é necessário avaliar se o projeto possui relevância científica, se contribuirá para a geração de conhecimento e se será exequível. 


\section{Revista Interdisciplinar de Pesquisa em Engenharia}

Não existe ainda, no Brasil, nenhuma norma que exija a submissão de projetos que utilizam animais à avaliação de um Comitê de Ética em Pesquisa. Porém, diversas instituições já demonstraram preocupação com este aspecto e implantaram alguma forma de ponderação destes projetos, seja através dos Comitês de Pesquisas já existentes, seja por meio da criação de comitês específicos para fins de avaliação de projetos que envolvem o uso de animais (RAYMUNDO, M. M; GOLDIM, 2015).

\section{BUSCA POR MÉTODOS ALTERNATIVOS NO MEIO CIENTÍFICO}

O uso de animais em experimentos é uma questão controversa, já que se constitui uma parte essencial das pesquisas de novas terapias e medicamentos, os quais proporcionam inúmeras possibilidades de aplicação para os mais diversos campos. Porém, os potenciais impactos negativos desse tipo de pesquisa acarretam numerosas preocupações políticas e culturais, principalmente no que diz respeito à relação entre os riscos e benefícios. Mais do que isso, os possíveis impactos geram uma preocupação com relação a questões mais amplas, como a alteração dos significados sociais, das identidades, das próprias formas de vida e do modo como nos relacionamos com elas (VICENTE, 2014).

Diferentemente do que muitos imaginam, o interesse por métodos alternativos cresce dentro da própria comunidade científica na tentativa de diminuir o número de animais utilizados em experimentação e também reduzir o custo dos experimentos, pois para se possa utilizar animais em pesquisa, é necessário que haja aparatos indispensáveis para a sobrevivência do animal, como a climatização ideal, a alimentação e a higienização. (MORALES, 2008).

Brown (BROWN, 2015) aponta a importância de centros ou grupos de pesquisa dedicados a métodos alternativos. Segundo o autor, mesmo aqueles que decidem seguir este caminho ainda encontrarão obstáculos e desafios, como problemas de financiamento e resistência de pessoas trabalhando fora dessas instituições.

Exemplos de alternativas ao uso de animais em pesquisa

Nos dias de hoje, métodos alternativos ao uso de animais têm se tornado cada vez mais viáveis e eficazes. Por conseguinte, diversos instrumentos estão sendo adotados. Dentre esses meios possíveis, encontram-se os seguintes instrumentos:

$\checkmark$ Cultivo de células in vitro: o cultivo de células, tecidos e órgãos é utilizado principalmente em pesquisa básica. Ele permite realizar estudos de câncer, imunologia, 


\section{Revista Interdisciplinar de Pesquisa em Engenharia}

testes toxicológicos, produção de vacinas, desenvolvimento de drogas, análise de doenças infecciosas, diagnose e observação de doenças ou distúrbios genéticos. Uma aplicação de extrema importância da cultura in vitro é na produção de vacinas, as quais são produzidas a partir de culturas de tecidos humanos. Por isso, as vacinas produzidas a partir de animais são mais seguras, já que evitam que vírus desconhecidos cruzem as barreiras das espécies e infectem o ser humano com outras doenças e disfunções.

$\checkmark$ Cultivo de microrganismos: microrganismos, tais como bactéria e protozoários, permitem realizar estudos de metabolismo, genética e bioquímica. Podem ser utilizados também para estimar os níveis de vitaminas em estudos farmacológicos e toxicológicos e identificar antibióticos.

$\checkmark$ Estudos Epidemiológicos: a epidemiologia é baseada em comparações. A partir dessas comparações, os pesquisadores obtêm indícios dos níveis de exposição ao fator investigado. Com estes estudos, conseguiu-se eliminar, ou reduzir, drasticamente a incidência de doenças infecto contagiosa, ao relacioná-las com as condições de higiene e saneamento.

$\checkmark$ Modelos matemáticos: modelos matemáticos podem contribuir para o trabalho experimental através da definição de variáveis e testando teorias (PIRES, 2013), reduzindo o custo desses experimentos e os tornando mais eficazes. Um exemplo disso é a predição, através de modelos matemáticos, da estrutura de proteínas, que poderiam prever suas propriedades físicas e químicas

$\checkmark$ Simulações computacionais: os computadores podem predizer reações biológicas causadas por drogas novas, baseados no conhecimento de sua estrutura tridimensional, eletrônica e química.

\section{RESULTADOS E DISCUSSÕES}

No total, foram encontrados 68 artigos, dos quais 37 apresentam os critérios de inclusão (mostrados na Tabela 1). Destes 37 artigos, 9 foram excluídos por apresentarem os critérios de exclusão (também mostrados na Tabela 2,) restando, assim, 28 trabalhos. O fluxograma da pesquisa pode ser visto na Figura 1.

Tabela 1 - Critérios de inclusão e exclusão.

\begin{tabular}{c|c}
\hline $\mathbf{N}^{\mathbf{0}}$ & Tipos de critérios \\
\hline & De inclusão \\
\hline
\end{tabular}




\section{Revista Interdisciplinar de Pesquisa em Engenharia}

\begin{tabular}{c|c}
\hline 1 & Trabalhos em língua Portuguesa ou Inglesa \\
\hline 2 & Trabalhos publicados em 10 anos \\
\hline 3 & Trabalhos que possuem uma avaliação ética do uso de animais em experimentos \\
\hline & De exclusão \\
\hline 1 & Trabalhos que não estimulem a diminuição da experimentação animal \\
\hline 2 & Trabalhos com foco em um tipo de animal \\
\hline
\end{tabular}

Fonte: Próprios autores.

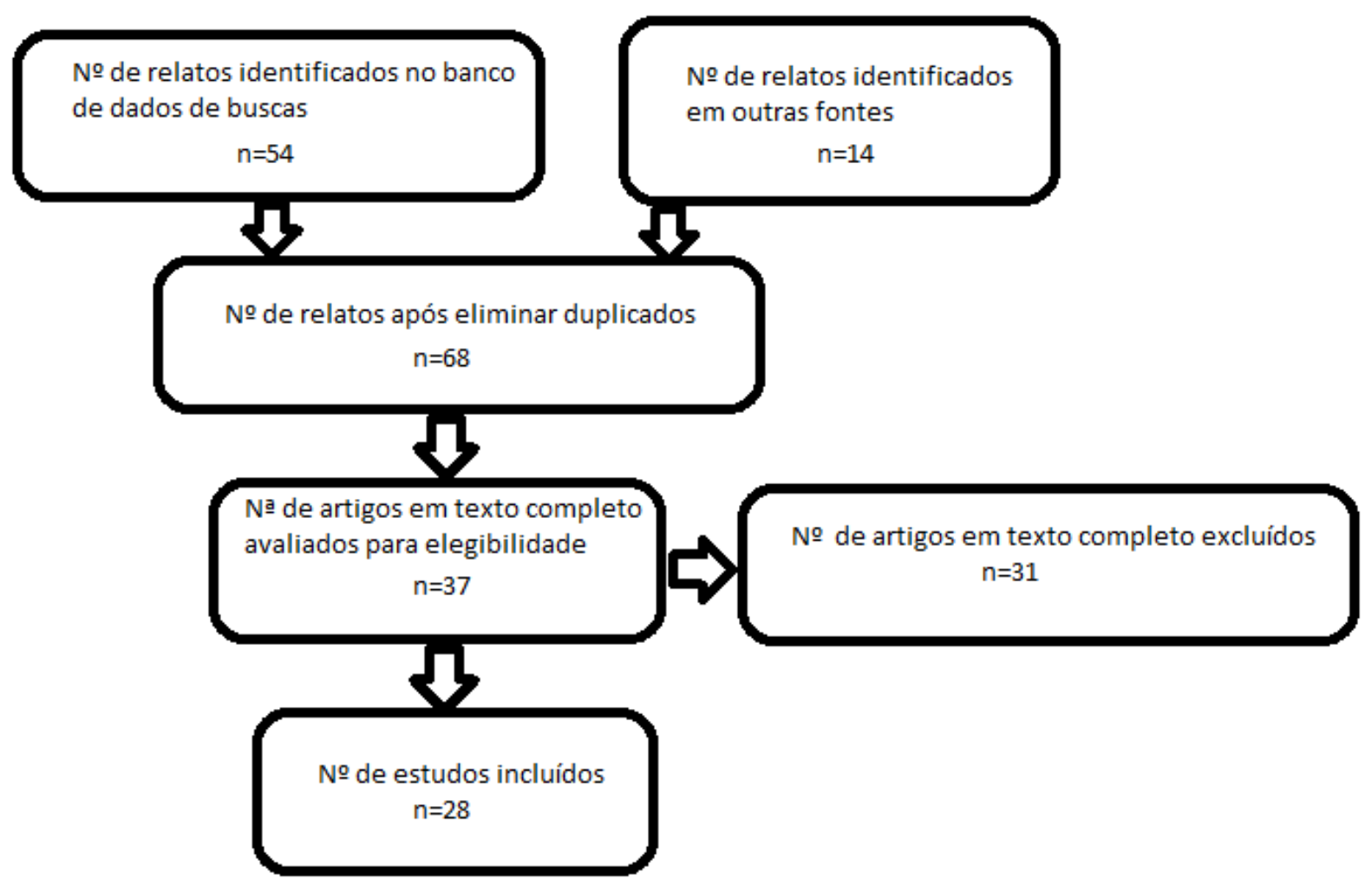

Figura 1 Fluxograma da pesquisa realizada

Fonte: Próprios autores

No âmbito da Universidade de Brasília, o Instituto de Biologia da Universidade de Brasília é composto por 8 Departamentos, a saber: departamento de botânica, botânica, ciências fisiológicas, genética e morfologia, fitopatologia, biologia celular, zoologia e nanobiotecnologia. Para a elaboração deste artigo, foi realizada pesquisa na biblioteca digital da UNB, buscando teses e dissertações disponibilizadas no ano de 2017 do Instituto de Ciências Biológicas com o objetivo de quantificar os trabalhos que utilizaram testes em animais ou in vitro. O resultado está apresentado na Tabela 2.

Tabela 1 - Testes in vitro e in vivo realizados em pesquisas de mestrado e doutorado do Instituto de Ciências Biológicas da UNB e defendidos no ano de 2017.

\begin{tabular}{l|l|l|l|l|l}
\hline Título do Trabalho & Programa & Ano & Teste & Cobaia & Autor \\
\hline
\end{tabular}




\section{Revista Interdisciplinar de Pesquisa em Engenharia}

\begin{tabular}{|c|c|c|c|c|c|}
\hline $\begin{array}{l}\text { Desenho, caracterização e } \\
\text { encriptação de peptídeos } \\
\text { bioativos como estratégia } \\
\text { para o processo de entrega e } \\
\text { otimização do perfil de } \\
\text { atividade. }\end{array}$ & $\begin{array}{l}\text { Pós-Graduação em } \\
\text { Biologia Molecular }\end{array}$ & 2017 & $\begin{array}{l}\text { In } \\
\text { vivo }\end{array}$ & Camundongos & (NÓBREGA, 2017) \\
\hline $\begin{array}{l}\text { Perfil taxonômico e } \\
\text { funcional microbiano em } \\
\text { ambientes aquáticos. }\end{array}$ & $\begin{array}{l}\text { Pós-Graduação em } \\
\text { Biologia } \\
\text { Microbiana }\end{array}$ & 2017 & $\begin{array}{l}\text { In } \\
\text { vitro }\end{array}$ & Micróbios & (LOPES, 2016) \\
\hline $\begin{array}{l}\text { Terapia fotodinâmica } \\
\text { mediada por cloreto } \\
\text { alumínio-ftalocianina em } \\
\text { nanoemulsões para } \\
\text { tratamento de pacientes com } \\
\text { queilite actínia: análise } \\
\text { clínica e histopatológica. }\end{array}$ & $\begin{array}{l}\text { Pós-Graduação em } \\
\text { Nanociência e } \\
\text { Nanobiotecnologia }\end{array}$ & 2017 & $\begin{array}{l}\text { In } \\
\text { vivo }\end{array}$ & Humanos & (LEITÃO, 2017) \\
\hline $\begin{array}{l}\text { Ensaio clínico para a } \\
\text { avaliação da segurança e } \\
\text { eficácia da terapia } \\
\text { fotodinâmica mediada por } \\
\text { nanoemulsão de al-cl- } \\
\text { ftalocianina no tratamento } \\
\text { do carcinoma basocelular de } \\
\text { pele. }\end{array}$ & $\begin{array}{l}\text { Pós-Graduação em } \\
\text { Nanociências e } \\
\text { Nanobiotecnologia }\end{array}$ & 2017 & $\begin{array}{l}\text { In } \\
\text { vivo }\end{array}$ & Humanos & $\begin{array}{l}\text { (ALBUQUERQUE, } \\
2017 \text { ) }\end{array}$ \\
\hline $\begin{array}{l}\text { Estratégias para integração } \\
\text { múltipla de cassetes de } \\
\text { expressão no genoma de } \\
\text { Komagataella phaffii. }\end{array}$ & $\begin{array}{l}\text { Pós-Graduação em } \\
\text { Biologia Molecular }\end{array}$ & 2017 & $\begin{array}{l}\text { In } \\
\text { vitro }\end{array}$ & DNA/RNA & $\begin{array}{l}\text { (BETANCUR, } \\
\text { 2017) }\end{array}$ \\
\hline $\begin{array}{l}\text { Regulação da biologia de } \\
\text { células dendríticas humanas } \\
\text { por Escherichia coli } \\
\text { uropatogênica (UPEC). }\end{array}$ & $\begin{array}{l}\text { Pós-Graduação em } \\
\text { Biologia } \\
\text { Microbiana }\end{array}$ & 2017 & $\begin{array}{l}\text { In } \\
\text { vitro }\end{array}$ & $\begin{array}{l}\text { Células } \\
\text { dendríticas }\end{array}$ & (MACIEL, 2017) \\
\hline $\begin{array}{l}\text { Avaliação in vitro da } \\
\text { inibição da atividade de } \\
\text { proteínas RAS por } \\
\text { derivados de quinolonas no } \\
\text { modelo câncer pancreático } \\
\text { humano. }\end{array}$ & $\begin{array}{l}\text { Pós-Graduação em } \\
\text { Biologia Molecular }\end{array}$ & 2017 & $\begin{array}{l}\text { In } \\
\text { vitro }\end{array}$ & $\begin{array}{l}\text { Células } \\
\text { Cancerígenas }\end{array}$ & (REDORAT, 2017) \\
\hline $\begin{array}{l}\text { Nanocápsulas com núcleo } \\
\text { de óleo de rícino e } \\
\text { invólucro de poli(metil vinil } \\
\text { co-anidrido maleico) } \\
\text { contendo doxorrubicina: } \\
\text { desenvolvimento e } \\
\text { avaliação de sua atividade } \\
\text { citotóxica contra células de } \\
\text { câncer de mama humano e } \\
\text { murino in vitro. }\end{array}$ & $\begin{array}{l}\text { Pós-Graduação em } \\
\text { Nanociência e } \\
\text { Nanobiotecnologia }\end{array}$ & 207 & $\begin{array}{l}\text { In } \\
\text { vitro }\end{array}$ & $\begin{array}{l}\text { Células } \\
\text { Cancerígenas }\end{array}$ & (COELHO, 2017) \\
\hline $\begin{array}{l}\text { Avaliação da atividade } \\
\text { como chaperona e do } \\
\text { potencial imunodiagnóstico } \\
\text { da proteína TCTP de } \\
\text { Paracoccidioides Spp. } \\
\end{array}$ & $\begin{array}{l}\text { Pós-Graduação em } \\
\text { Biologia Molecular }\end{array}$ & 2017 & $\begin{array}{l}\text { In } \\
\text { vitro }\end{array}$ & Fungos & (MAIA, 2017) \\
\hline $\begin{array}{l}\text { Efeitos de combinações } \\
\text { entre o ácido anacárdico } \\
\text { derivado da casca da } \\
\text { castanha do caju } \\
\text { (Anacardium occidentale) e }\end{array}$ & $\begin{array}{l}\text { Pós-Graduação em } \\
\text { Naniciência e } \\
\text { Nanobiotecnologia }\end{array}$ & 2017 & $\begin{array}{l}\text { In } \\
\text { vitro }\end{array}$ & $\begin{array}{l}\text { Células } \\
\text { Cancerígenas }\end{array}$ & (ARAÚJO, 2017) \\
\hline
\end{tabular}




\section{Revista Interdisciplinar de Pesquisa em Engenharia}

\begin{tabular}{|c|c|c|c|c|c|}
\hline $\begin{array}{l}\text { o óleo de açaí (Euterpe } \\
\text { oleracea Mart.), livres ou } \\
\text { nanoestruturados, no } \\
\text { tratamento de células de } \\
\text { câncer de pele não } \\
\text { melanoma, in vitro. }\end{array}$ & & & & & \\
\hline $\begin{array}{l}\text { Nanopartículas de prata na } \\
\text { presença de ácido húmico } \\
\text { em meio aquoso: } \\
\text { caracterização físico- } \\
\text { química e avaliação } \\
\text { toxicológica em modelo } \\
\text { zebrafish (Danio rerio). }\end{array}$ & $\begin{array}{l}\text { Programa de Pós- } \\
\text { Graduação em } \\
\text { Biologia Animal }\end{array}$ & 2017 & $\begin{array}{l}\text { In } \\
\text { vivo }\end{array}$ & Peixes & (VÉLEZ, 2017) \\
\hline $\begin{array}{l}\text { O papel do sistema de } \\
\text { secreção do tipo VI (TSS6) } \\
\text { bacteriano na ativação dos } \\
\text { inflamassomas durante a } \\
\text { resposta imunológica inata. }\end{array}$ & $\begin{array}{l}\text { Programa de Pós- } \\
\text { Graduação em } \\
\text { Biologia Molecular }\end{array}$ & 2017 & $\begin{array}{l}\text { In } \\
\text { vivo }\end{array}$ & Camundongos & (RIBEIRO, 2017) \\
\hline $\begin{array}{l}\text { Desenvolvimento e } \\
\text { aplicação biológica de } \\
\text { nanossistemas contendo o } \\
\text { fotossensibilizante cloreto } \\
\text { de alumínio ftalocianina. }\end{array}$ & $\begin{array}{l}\text { Pós-Graduação em } \\
\text { Biologia Animal }\end{array}$ & 2017 & $\begin{array}{l}\text { In } \\
\text { vivo }\end{array}$ & Camundongos & $\begin{array}{l}\text { (PY-DANIEL, } \\
2017)\end{array}$ \\
\hline $\begin{array}{l}\text { Desenvolvimento e } \\
\text { caracterização de } \\
\text { nanoemulsões à base de } \\
\text { óleo de buriti (Mauritia } \\
\text { flexuosa) para avaliação de } \\
\text { efeitos biológicos em } \\
\text { células de câncer de mama } \\
\text { in vitro. }\end{array}$ & $\begin{array}{l}\text { Pós-Graduação em } \\
\text { Nanociência e } \\
\text { Nanobiotecnologia }\end{array}$ & 2017 & $\begin{array}{l}\text { In } \\
\text { vitro }\end{array}$ & $\begin{array}{l}\text { Células } \\
\text { Cancerígenas }\end{array}$ & (SAMPAIO, 2017) \\
\hline $\begin{array}{l}\text { Tratamento de câncer de } \\
\text { mama utilizando terapia } \\
\text { fotodinâmica com } \\
\text { nonoemulsões de } \\
\text { Ftalocianina de cloro } \\
\text { alumínio. }\end{array}$ & $\begin{array}{l}\text { Pós-Graduação em } \\
\text { Nanociência e } \\
\text { Nanobiotecnologia, }\end{array}$ & 2017 & $\begin{array}{l}\text { In } \\
\text { vivo }\end{array}$ & Camundongos & (MOURA, 2017) \\
\hline
\end{tabular}

Fonte: Biblioteca Digital da UNB.

Na Tabela 2 observa-se um número equilibrado de trabalhos envolvendo testes in vitro e in vivo. Esse fenômeno pode ser explicado pelo estágio de cada pesquisa. Para que um trabalho possa realizar testes in vivo é preciso que haja a sua respectiva aprovação pelo comitê de ética da Universidade, comitê este que avalia se já foram realizados testes sem a utilização de animais relacionados ao tema. Sendo assim, os trabalhos que desenvolveram testes in vivo apresentados na Tabela 2 utilizaram como justificativa o estágio seguinte após resultados promissores durante testes in vitro realizados anteriormente no meio científico.

A ciência biomédica possui diversos métodos que foram inicialmente testados em animais. Franco (FRANCO et al., 2014) divide o uso de animais em três áreas: ensino, pesquisa e teste de produtos. Dentre essas três áreas, é comum a prática de vivisseção em faculdades 


\section{Revista Interdisciplinar de Pesquisa em Engenharia}

biomédicas, testes de novas drogas e procedimentos cirúrgicos e avaliação de graus de toxidade em cosméticos, produtos alcoólicos, tabaco e até mesmo de armas químicas.

Deste modo, uma tendência que cada vez mais torna-se realidade no meio científico é o uso de alternativas que não envolvam a utilização de animais para a realização de experimentos e atividades didáticas. Por outro lado, alguns cientistas afirmam que o emprego de animais para testes de novas drogas, métodos, tratamentos e produtos é insubstituível. Estes cientistas defendem que a tecnologia existente atualmente não é capaz de substituir por completo o uso de animais em experimentos.

A legislação contribui para o desenvolvimento de alternativas relacionadas ao bem-estar animal, tanto em pesquisas quanto no ensino. Ressalta-se que isto já é uma realidade no cenário brasileiro, tendo em vista que estudos nacionais demonstram possibilidades para a substituição do uso de cobaias por métodos alternativos.

\section{CONCLUSÕES}

A experimentação animal é um tema controverso no meio científico. A decisão de utilizar animais em pesquisa biomédica é uma discussão complexa, tanto no âmbito ético, como no filosófico.

Muitos cientistas defendem as vantagens do uso de animais para experimentação, tendo como argumentos que todas as descobertas para prevenção de doenças e sua consequente cura se devem a experimentação animal, além de novas técnicas cirúrgicas e controle de produtos farmacêuticos, provenientes da mesma fonte de experimentação. Por outro lado, estes mesmos pesquisadores que não abrem mão do uso de animais em suas pesquisas, já admitem que o uso de animais deve ser racionalizado.

Embora a tecnologia atual não permita erradicar a experimentação animal, a utilização de métodos alternativos ao uso de animais em projetos de pesquisa deve sempre ser encorajada, para que haja o favorecimento da abordagem humanitária das práticas científicas, evitando, assim, o sofrimento de um grande número de animais e auxiliando na conscientização sobre o respeito à vida em todas as suas formas e manifestações.

\section{Referências Bibliográficas}

ALBUQUERQUE, I. O. DE. Ensaio clínico para a avaliação da segurança e eficácia da terapia fotodinâmica mediada por nanoemulsão de al-cl-ftalocianina no tratamento do 
carcinoma basocelular de pele. [s.1.] Universidade de Brasília, 2017.

ARAÚJO, H. L. L. DE. Efeitos de combinações entre o ácido anacárdico derivado da casca da castanha do caju (Anacardium occidentale) e o óleo de açaí (Euterpe oleracea Mart.), livres ou nanoestruturados, no tratamento de células de câncer de pele não melanoma, in vitro. [s.l.] Universidade de Brasília, 2017.

BETANCUR, M. O. Estratégias para integração múltipla de cassetes de expressão no genoma de Komagataella phaffii. [s.1.] Universidade de Brasília, 2017.

BROWN, K. The cost of standing strong for replacement. Alternatives to laboratory animals : ATLA, v. 43, n. 1, p. P5-P7, 2015.

CHAN, A. D. C. et al. A Reflection on Biomedical Engineering Ethics Education from Multiple Perspectives. Ethics in Biology, Engineering and Medicine: An International Journal, v. 4, n. 3, p. 199-209, 2013.

CHELUVAPPA, R.; SCOWEN, P.; ERI, R. Ethics of animal research in human disease remediation, its institutional teaching; and alternatives to animal experimentation.

Pharmacology Research and Perspectives, v. 5, n. 4, p. 1-14, 2017.

COELHO, J. M. Nanocápsulas com núcleo de óleo de rícino e invólucro de poli(metil vinil co-anidrido maleico) contendo doxorrubicina: Desenvolvimento e avaliação de sua atividade citotóxica contra células de câncer de mama humano e murino in vitro. [s.l.] Universidade de Brasília, 2017.

FRANCO, A. L. et al. Pesquisas em animais: uma reflexão bioética. Acta Bioethica, v. 20, n. 2, p. 247-253, 2014.

LANDI, M. S.; SHRIVER, A. J.; MUELLER, A. Consideration and checkboxes: incorporating ethics and science into the 3 Rs. Journal of the American Association for Laboratory Animal Science, v. 54, n. 2, p. 224-30, 2015.

LEITÃO, E. C. DE V. Terapia fotodinâmica mediada por cloreto alumínio-ftalocianina em nanoemulsões para tratamento de pacientes com queilite actínica : análise clínica e histopatológica. [s.1.] Universidade de Brasília, 2017.

LOPES, F. A. C. Perfil taxonômico e funcional microbiano em ambientes aquáticos. [s.l.] Universidade de Brasília, 2016.

MACIEL, E. P. Regulação da biologia de células dendríticas humanas por Escherichia coli uropatogênica (UPEC). [s.l.] Universidade de Brasília, 2017.

MAIA, L. J. Avaliação da atividade como chaperona e do potencial imunodiagnóstico da proteína TCTP de Paracoccidioides Spp. [s.1.] Universidade de Brasília, 2017.

MEDEIROS, F. L. F.; ALBUQUERQUE, L. Experimentação Animal: Um Combate Jurídico nas Universidades Brasileiras. p. 65-83, 2015.

MORALES, M. M. Métodos alternativos à utilização de animais em pesquisa científica: mito ou realidade? Ciência e Cultura, v. 60, n. 2, p. 33-36, 2008.

MOURA, L. D. DE. Tratamento de câncer de mama utilizando terapia fotodinâmica com nonoemulsões de Ftalocianina de cloro alumínio. [s.1.] Universidade de Brasília, 2017.

NÓBREGA, M. M. Desenho, caracterização e encriptação de peptídeos bioativos como 
estratégia para o processo de entrega e otimização do perfil de atividade. [s.l.]

Universidade de Brasília, 2017.

PAIXÃO, R. L. As Comissões de Ética no uso de animais. Journal of Chemical

Information and Modeling, v. 53, n. 9, p. 1689-1699, 2013.

PAIXÃO, R. L.; SCHRAMM, F. Experimentação Animal: Razões E Emoções Para Uma Ética. 2001.

PIRES, J. G. Na importância da biologia em engenharias : biomatemática e bioengenharias. XX Simpósio de Engenharia de Produção, p. 1-12, 2013.

PY-DANIEL, K. R. Desenvolvimento e aplicação biológica de nanossistemas contendo o fotossensibilizante cloreto de alumínio ftalocianina. [s.l.] Universidade de Brasília, 2017.

RAYMUNDO, M. M; GOLDIM, J. R. O Uso De Animais Em Pesquisas Científicas.

Statewide Agricultural Land Use Baseline 2015, v. 1, n. 3, p. 1-8, 2015.

REDORAT, F. S. Avaliação in vitro da inibição da atividade de proteínas RAS por derivados de quinolonas no modelo câncer pancreático humano. [s.l.] Universidade de Brasília, 2017.

RIBEIRO, D. J. S. O papel do sistema de secreção do tipo VI (TSS6) bacteriano na ativação dos inflamassomas durante a resposta imunológica inata. [s.1.] Universidade de Brasília, 2017.

RICOU, M. M.; MESTRADO, C. DE. Rodrigo Muniz da Silva Experimentação Animal : Objeção ao Sacrifício do Outro. [s.l: s.n.].

SAMPAIO, M. C. Desenvolvimento e caracterização de nanoemulsões à base de óleo de buriti (Mauritia flexuosa) para avaliação de efeitos biológicos em células de câncer de mama in vitro. [s.l.] Universidade de Brasília, 2017.

VÉLEZ, P. R. C. Nanopartículas de prata na presença de ácido húmico em meio aquoso : caracterização físico-química e avaliação toxicológica em modelo zebrafish (Danio rerio). [s.1.] Universidade de Brasília, 2017.

VICENTE, A. M. Core Set E Participação Pública. 2014.

ZWOLIŃSKA, J. The use of animals in experiments. Ethics of animal use, p. 103-117, 2013. 